\title{
L@s niñ@s buen@s hacen los deberes (L@s mal@s, copian de Internet)
}

\author{
Rufino SÁNCHEZ* \\ rufino.sanchez@rtve.es
}

(Abstracts y palabras clave al final del artículo)

Enviado: 12 de marzo de 2013

Evaluado: 20 de marzo de 2013

Aceptado: 25 de marzo de 2013

\section{INTRODUCCION}

Los medios de comunicación no viven su mejor momento. Cierto es que nada ni nadie vive su mejor momento, pero quienes nos ganamos (o intentamos ganarnos) la vida trabajando en lo que se denomina "industrias de la información" acusamos una doble crisis: la económica, la que afecta a todos en general y tiene a cinco millones de españoles esperando turno a las puertas del INEM, según datos de marzo de 2013 (Ministerio de Empleo y Seguridad Social, 2013); y la nuestra, una particular que comenzó mucho antes de que el ladrillo y la inversión inmobiliaria arrastrasen nuestras cuentas al fondo del abismo. Antes, incluso, de que la prima de riesgo (término tan común hoy, y tan desconocido hace apenas 5 años) se convirtiese en la reina de los informativos. Los periodistas vivimos en crisis desde mucho antes, pero, qué duda cabe, el actual y desolador panorama social de este país nos ha hecho batir todos los récords de desempleo, precariedad y miseria salarial.

$\mathrm{Al}$ analizar nuestro presente en ruinas uno puede optar por un enfoque económico:

"El beneficio después de impuestos del conjunto de los diarios españoles en 2008 fue de 11,9 millones de euros, un 95\% menos que los 232,9 millones obtenidos en el ejercicio anterior [...] Los editores achacaron los malos resultados al brusco parón de la venta bruta de publicidad [...] Va a ser muy difícil que la inversión publicitaria vuelva a los niveles que tenía en 2007, aseguró Antonio Fernández-Galiano, Presidente de AEDE (Asociación de Editores de Diarios Españoles) De hecho, no vaticinó una recuperación completa antes de 2015" (TOLEDO, DANIEL, 2009).

Podemos pensar que parte de la culpa de nuestros problemas la tiene una planificación universitaria que no tiene en cuenta el mercado laboral y licencia a muchos más periodistas de los que podrán trabajar como tales:

\footnotetext{
* Rufino Sánchez es doctorando en el Departamento de Periodismo III, UCM, Madrid.
} 
"El Mundo despide 164 redactores y los suple con 90 becarios. El ERE de Unidad Editorial que significó la salida de 164 empleados sigue generando polémicas. [...] los sindicatos señalan que después de haber despedido a 164 personas, la empresa ha decidido que muchos becarios pueden realizar el mismo trabajo que los redactores sobre todo en internet-, aunque no tengan ninguna experiencia profesional, y les ha prorrogado los tres meses de prácticas de verano hasta que completen un año" (PR NOTICIAS, 2010)

Pero de todos los posibles enfoques que se pueden escoger a la hora de estudiar esta delicada y preocupante situación profesional nosotros queremos reflexionar a propósito de nuestra parte de culpa. Seamos francos, los periodistas no somos un colectivo dado a la autocrítica, no nos caracterizamos por la humildad, más bien todo lo contrario. Una encuesta rápida a quienes trabajan con nosotros todos los días y no son periodistas (los operadores de cámara, los técnicos de sonido, maquetadotes, diseñadores gráficos, etc) nos permitirá descubrir que los demás nos ven como gente preparada pero con un ego hipertrofiado que nos impide practicar el sano ejercicio de la autocrítica. Practiquémoslo juntos. ¿Por qué atraviesa la profesión periodística una de las peores crisis de su historia? Porque ésta es, en parte, una crisis de prestigio, de imagen. Últimamente no hemos hecho muy bien los deberes.

\section{TODO LO QUE QUEREMOS ES JUEGO LIMPIO Y NEUTRALIDAD}

Esta frase, ("Todo lo que queremos es juego limpio y neutralidad"), está sacada de un estudio publicado por la Asociación Americana de Editores de Periódicos (ASNE - American Society of Newspaper Editors). Con dicho informe se pretendía averiguar cómo veían los norteamericanos a los periodistas y la prensa escrita ${ }^{1}$. Y las conclusiones permiten dibujar dos talones de Aquiles peligrosos para nuestra profesión: el servilismo o intoxicación ideológica de la información, y la relajación (hasta niveles imperdonables) en cuanto a rigor, tratamiento de las fuentes e, incluso, redacción y gramática.

El primero, el servilismo, es un problema que arrastramos desde el principio de los tiempos. Según el citado, y otros, informes de la ASNE, los lectores de periódicos ven a los periodistas como profesionales "mejor informados" que los ciudadanos de a pie, pero con pocos escrúpulos a la hora de conseguir primicias y publicar exclusivas. Profesionales que, además, han dejado a un lado la tradicional división de géneros información-opinión, presionados por políticos, anunciantes y otros organismos de poder:

\footnotetext{
1 "El público sospecha que el punto de vista y las tendencias de los periodistas influyen en el tratamiento de las historias y en cómo ellos mismos son tratados. [...] Todo lo que queremos es juego limpio y neutralidad, por favor, guarde sus opiniones para la página editorial, es lo que dicen los americanos"

"The public suspects that the points of view and biases of journalists influence what stories are covered and how they are covered. [...] All we sant is fair play and neutrality, and please keep your opinions on the editorial page, Americans say" (ASNE, 1999)
} 
"El 78 por ciento del público cree que gente con poder y organizaciones pueden influir en un periódico hasta el punto de hacer girar una historia. Los grupos que el público cita con más frecuencia a la hora de hablar de posibles influencias en la creación de noticias son políticos, organismos gubernamentales, grandes empresarios y personas adineradas. El $50 \%$ cree que los intereses de los anunciantes también influyen en las decisiones. Un punto de vista crítico (compartido por el 59\% del público) es que los periódicos están más preocupados por obtener beneficios que en servir al interés público $2,3 "$ (ASNE, 1998)

Este grave defecto que los lectores de periódicos norteamericanos observan en la prensa escrita de su país podemos encontrarlo también en los medios españoles. En este país los periodistas llegamos a admitir ruedas de prensa sin preguntas (prácticas habituales de políticos como Mariano Rajoy y Alfredo Pérez Rubalcaba) y nuestro enfoque, e incluso las palabras que escogemos en nuestros artículos, dependen (salvo en el caso de grandes nombres propios) de la línea editorial del medio en el que trabajemos.

No es de extrañar que, tal y como asegura Pilar Díezhandino, la gente "tienda a confiar cada vez menos en el Periodismo". Es inevitable reconocer que, en parte, "se ha extendido la convicción de que el periodismo no está respondiendo a la prioridad del interés público y de la búsqueda de veracidad4". En parte por la "peligrosa cesión que muchos contenidos, apellidados periodísticos, están haciendo al conformismo, la canalización, la espectacularización, al predominio de lo inverificable o inverificado" (DIEZHANDINO, M. Pilar, 2007: 15-25)

Y si peligroso es para nuestra profesión que el público nos vea como periodistas vendidos, sin escrúpulos, sensacionalistas y conformistas, no lo es menos que piense de nosotros que somos estúpidos:

"Más de una tercera parte de los adultos (norteamericanos) dicen haber visto errores de ortografía y gramática en los periódicos que leen más de una vez a la semana. Y el 21\% dice que los ve a diario. Es como si la prensa escrita se hubiese vuelto cada vez más estúpida en los últimos 10 años, dice uno de los encuestados ${ }^{5}$ " (ASNE, 1998)

2 DEA Universidad Complutense de Madrid

3 "78 percent of the public believes that powerful people or organizations can influence a newspaper to "spike or spin" a story. The most frequently cited groups the public thinks influence news decisions are politicians or government officials, big business and wealthy individuals. Half (50 percent) believe that advertisers ${ }^{\text {e }}$ interests influence decisions. A big criticism (felt by 59 percent of the public) is that newspapers are concerned mainly with making profits, rather than serving the public interest"

${ }^{4}$ Dice Diezhandino que "profesionales felizmente dependientes" de editores, empresarios, agencias de noticias y gabinetes de prensa; una agenda mediática en manos de los "productores de noticias"; el exceso de institucionalización; el recurso a la valoración ideológica como diferencia entre medios; la uniformidad temática; la ausencia de fuentes y la politización de la cobertura informativa, entre otros aspectos igualmente lamentables, son las causas del actual descrédito de la profesión periodística. (DIEZHANDINO, M. Pilar, 2007: 15-25)

5 "More than a third of adults said they see spelling or grammar mistakes in their newspaper more than once a week, and 21 percent said the see them almost daily. It seems like the paper's gotten sloppier in the last 10 years, said one focus group participant". 
Los periodistas nos equivocamos desde el principio de los tiempos, pero en la era del ciberespacio, la web 2.0, youtube y wikipedia, prolifera en las redacciones un nuevo tipo de error frecuente y preocupante, que afecta por igual a jóvenes y veteranos, y ante cuya evidencia el afectado suele encogerse de hombros y responder con incredulidad: "pues yo lo leí en Internet".

\section{ERRARE HUMANUM EST...}

...Aunque es algo que a veces se nos olvida. Pensamos que el error es propio de profesionales mediocres o ignorantes, y que si nos equivocamos pensarán de nosotros que somos uno u otro. Quien esto escribe cometió hace poco un error de récord: dije de los últimos Premios Laureus del deporte, que se celebraron el lunes once de marzo de 2013, en Río de Janeiro, que se entregaban "bajo la atenta mirada del Cristo de Corcovado, con vistas a la bahía de Guanabara, a orillas del Océano Pacífico". No me di cuenta del enorme error que cometía hasta que escuché mi propia voz pronunciándolo en el reportaje, mientras se emitía por televisión. Ni al escribirlo, ni al locutarlo, ni al montarlo caí en la cuenta de que estaba dándole la vuelta al mapa de América. Exactamente un millón quinientos veintiséis mil espectadores veían el canal en ese momento, según datos de Sofres.

Es un tipo de error que podríamos calificar como lapsus: sé perfectamente que es el Océano Atlántico el que baña las cosas orientales de Brasil, pero mientras escribía mi mente dictó "Pacífico" a mis dedos y no se me ocurrió contrastar un dato tan aparentemente obvio.

Este tipo de error se cometía, se comete y se cometerá. Pero nos parece mucho más interesante el que tiene que ver con la tendencia a convertir Internet en la fuente de información prioritaria y, en ocasiones, única de un periodista. La fiabilidad de un periodista y de su información depende de la fiabilidad de sus fuentes y, si echamos mano a lo que nos dicen los estudiosos de los medios desde el principio de los tiempos, no se puede considerar como rigurosa una fuente sin autor identificado:

"Todo relato informativo debe indicar la fuente o las fuentes de información de donde proceden los datos y los juicios. Las fuentes deben ser identificadas con la mayor precisión posible. Las valoraciones, comentarios y apreciaciones que aparecen dentro de un relato informativo tienen que estar necesariamente referidas a una fuente" (Martínez Albertos; Santamaría, 1996:123)

Si un periodista no puede incluir en su relato informativo la identidad de su fuente porque la desconoce (otra cosa es que la conozca pero se vea en la obligación o necesidad de no desvelarla) debe preguntarse muy seriamente si la información que maneja puede ser considerada una fuente fiable. Porque si no sabemos de dónde viene y quién nos la hace llegar nos arriesgamos a cometer errores tan graves como los que se cometieron en la segunda edición del Telediario de la primera cadena de Televisión Española el 13 de enero de 2010. 
El informativo abría con imágenes del terremoto de Haití (sin concretar su procedencia) (RTVE, 2010, minuto 0.10) y poco más tarde se dedicaba una noticia entera a los primeros momentos del seísmo tal y como los habían vivido las víctimas. Es en este momento cuando se hace mención indirecta a la procedencia de las imágenes:

"Es el momento del terremoto, en este vídeo de aficionado se aprecia como una construcción se desploma por completo, y el terrible estruendo" (RTVE, 2010, minuto 7.56 )

$\mathrm{Ni}$ en la entradilla, ni en la información se compartía con el espectador que, si bien las imágenes habían sido captadas por un video aficionado, los responsables del telediario las habían obtenido a través de Internet. En concreto a través del canal de vídeos Youtube. (EL PAÍS, 2010)

"El momento del terremoto" como aseguraba la redactora en su información, era, en realidad una tormenta en Venecia, y la "construcción que se desploma" parte de la estructura que conformaba el escenario de un festival musical celebrado en la ciudad italiana.

Los responsables informativos cometerían un error similar apenas unos minutos más tarde: "Es el puente que unía los pueblos de Viso y San Lorenzo de Calatrava, en Ciudad Real" de esta manera se presentan imágenes procedentes de un "vídeo doméstico" grabado durante las riadas "que hace dos semanas se lo llevaron por delante, el agua arrastra la tierra, rompe el asfalto y hace desaparecer, finalmente, como ven, la carretera" (RTVE, 2010, minuto 40.34)

La gran pega del vídeo es que la tierra "arrastrada", el asfalto "roto" y la carretera "desaparecida" no se encontraban en la provincia de Ciudad Real, sino en Estados Unidos. (EL PAÍS, 2010). Al día siguiente llegaría el momento de las rectificaciones. En el Telediario y en la página web, dónde se podía leer lo siguiente:

"Televisión Española, dentro del amplio despliegue que hizo en sus ediciones de este miércoles para informar sobre el terremoto de Haití, emitió imágenes que no se correspondían con este suceso. Se trata de un video de Youtube que se captó a través de internet. La dirección de TVE lamenta enormemente este error y pide disculpas por ello. Mientras se investiga el hecho, se ha reactivado el protocolo de máximo contraste cuando se utilizan imágenes vertidas en la Red" (RTVE, 2010)

"El protocolo de máximo contraste" es una forma grandilocuente de referirse a algo que, en realidad, no debería hacer falta recordar porque es norma básica del periodista: hay que contrastar la información de nuestras fuentes, mucho más en caso de materiales hallados en Internet.

La razón de los errores cometidos por el Telediario fue, una vez más, la dificultad y, en ocasiones, imposibilidad de contrastar lo que encontramos en Internet. Alguien (un usuario anónimo y mal intencionado) subió las imágenes al portal audiovisual youtube cambiando el título original de las mismas por uno mucho más a tono con la actualidad del momento, confundiendo a la redacción de informativos de Televisión Española. Y aunque la mala fe es evidente, no supone excusa ninguna 
para los editores del Telediario, puesto que el mismo vídeo que dieron por válido para ilustrar la tragedia de Haití ya había sido utilizado por malintencionados usuarios de la Red para confundir a los medios un año antes: fue colgado en el servidor de imágenes de Google y se atribuyó al tsunami de Samoa.

Lo de la Red como medio de documentación fue, como se suele decir, llegar y besar el santo. Estudios de hace 10 años aseguraban que ya por aquel entonces el $92 \%$ de los profesionales de la información usábamos Internet para buscar noticias o temas nuevos. Y eso que por aquel entonces ya despertaba nuestras suspicacias: los encuestados aseguraban que su confianza en las web era menor que en fuentes tradicionales e intentaban contrastar siempre todo lo leído en Internet, aunque "la presión de la rapidez haya supuesto en ocasiones la publicación de informaciones sin confirmar con todas las controversias que supone actuar de este modo" (Rubio, Noelia, 2001: 11)

Internet altera el tradicional esquema "Fuente-Periodista-Lector" y democratiza el papel de emisor de la comunicación. Eso no sólo quiere decir que los lectores querrán intercambiar información entre ellos, también que las fuentes desearán llegar al público sin la necesidad de que un periodista ejerza de intermediario. Y ante tal profusión de fuentes sublevadas, usuarios ejerciendo de reporteros, redes sociales y demás parafernalia web, el periodista profesional debe extremar la precaución con todo aquello que "consume" para su trabajo diario.

"Accuracy, accuracy, accuracy" (exactitud, exactitud, exactitud) Esas eran las tres normas básicas que todo periodista debía seguir en su trabajo según Joseph Pulitzer. Melvin Mencher lo recuerda y las recomienda, además, para evitar querellas y demandas. (Mencher, Melvin, 2003: 591)

Pero no hay que pensar sólo en problemas legales, ser riguroso en nuestro trabajo es una cuestión de pundonor profesional, respeto al público y amor propio periodístico. No sólo es nuestra obligación comprobar que la información es verídica. Para Gaye Tuchman, el profesional de la comunicación debe hacer un análisis muy profundo respecto a sus fuentes: ¿Por qué y para qué se me ha proporcionado esta información?:

"La mayoría de las personas, incluidas las fuentes informativas, sirven a sus fines particulares [...] por ejemplo los presidentes de consejos, están en situación de conocer mejor que otras personas una organización. Aunque puedan servir a sus intereses personales su información será probablemente más exacta porque tienen más hechos a su disposición [...] Las instituciones y organizaciones tiene procedimientos dispuestos para proteger tanto a la institución como a las personas que entran en contacto con ella. La importancia de una declaración o de un sin comentarios debe siempre establecerse de acuerdo con el conocimiento que el periodista tenga de esos procedimientos institucionales" (Tuchman, Gaye, 1998-1999: 50)

En Internet se diluye la figura del creador, generándose una sensación de anonimato respecto a la elaboración del contenido web, ¿Cómo puede llegar a averiguar el periodista cuales son los intereses de su fuente si en determinados casos es difícil identificarla? Otra razón más por la que toda página web cuyo autor no esté correctamente identificado debe ser descartada como fuente fiable de información. ¿Qué 
hacemos entonces con Wikipedia? Sus artículos no tienen firma. Es una creación comunitaria, de redactores anónimos y editores que se ven claramente sobrepasados por el volumen de trabajo.

\section{PSEUDO ENCICLOPEDIAS}

Dos años ha permanecido alterada la lista de los Reyes Godos en Wikipedia. Lo sé porque la alteré yo mismo en junio de 2010. Los tres primeros reyes de la lista original eran Ataulfo, Sigerico y Walia, que reinaron entre los años 410 y 415, en 415 y entre 415 y 418 respectivamente. En la lista modificada presentó, desde junio de 2010 hasta el verano de 2012, sin que nadie notase la diferencia, el orden alterado. Walia fue el primero de la lista, entre el año 410 y el 415, le seguía Ataulfo, que reinó, según esta tabla adulterada en 415 y cerraba la lista Sigerico, Rey de los Godos, gracias a nuestra modificación, entre 415 y 418 . En noviembre de 2011 el error persistía. A comienzos de 2012 también, ese verano fue corregido. (Imágenes 1 y 2)

Imagen 1
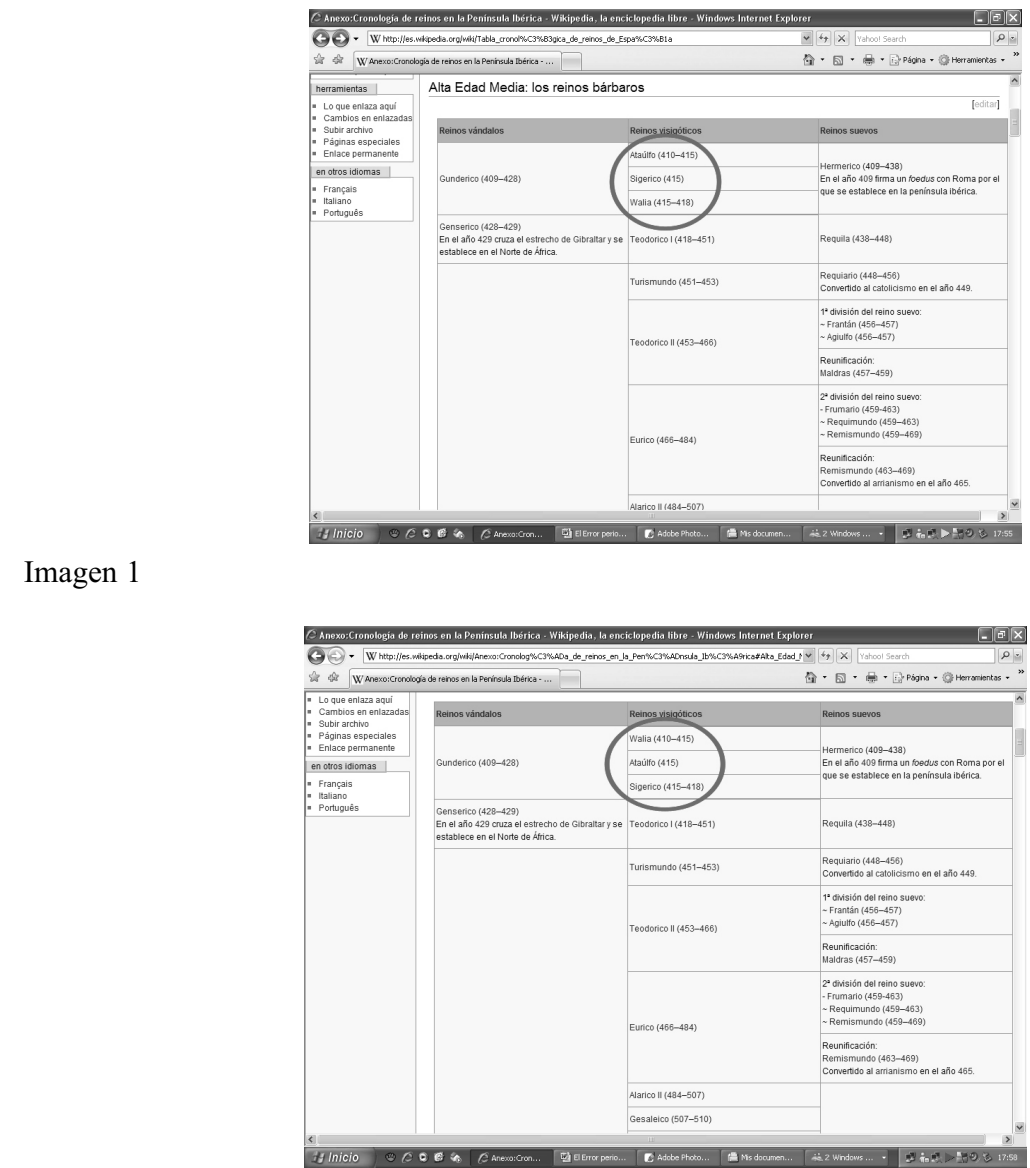

Imagen 2 
Impulsada por Jimmy Wales y Larry Sanger, Wikipedia es, para muchos, el maravilloso compendio de todo cuanto uno necesita saber en el mundo. Para otros se trata de un enorme vertedero informativo en el que separar grano de paja es tan difícil como atravesar un campo de minas. Su funcionamiento es sencillo: cualquiera puede escribir un artículo sobre un tema que no figure en sus "páginas" o corregir el contenido de alguno redactado previamente por otro usuario. El registro es sencillo, innecesario, incluso, si lo que deseas es simplemente corregir, y al terminar tu trabajo la página simplemente te pedirá que expliques, en caso de haber modificado alguna información ya existente, por qué razón lo has hecho (si es porque la considerabas errónea o incompleta) Así de sencillo, y sobre todo, de anónimo.

Después tu escrito pasa a formar parte de la enciclopedia virtual y cualquier persona puede consultarlo (y a partir de este momento, también, corregirlo)

Wikipedia confía en una lógica de edición sencilla y, en teoría, efectiva: basta el gran volumen de internautas -410 millones de visitantes únicos al mes según datos de noviembre de 2010- (Delclós, Tomás, 2010) que pueden llegar a leer sus artículos a diario para que un error no permanezca publicado demasiado tiempo. Dicho en otras palabras cuatro ojos ven más que dos. El 29\% de las correcciones proviene de este método en su edición en español. Por si acaso el tráfico de visitas no es suficiente, un número de editores (conocidos como bibliotecarios) revisan las entradas de manera periódica: en España hay 140. Son los encargados de supervisar los más de 800.000 artículos (que se incrementan en unos 400 al día) que conforman la edición en castellano de Wikipedia, la cuarta del mundo en número de visitas. ( Delclós, Tomás, 2011)

Cuatro ojos ven más que dos pero la lista de horrores de Wikipedia empieza a ser extensa: una hora antes de conocerse el nombre del Premio Nobel de Literatura de 2010, en Wikipedia ya le habían adjudicado el premio al sueco Tomas Tranströmer (el premio fue, finalmente, para Mario Vargas Llosa); Y no sólo se pueden cometer equivocaciones accidentales, en febrero de 2009 el barón $\mathrm{Zu}$ Guttenberg asumía la cartera de economía en el Gobierno alemán y alguien modificó su artículo de Wikipedia para introducir, entre sus nombres de pila, el de Wilhelm (Guillermo) ese mismo día aparecía con ese nombre en las noticias de numerosos medios de comunicación. (Bitacoras.com en ABC, 2011)

Algunas manipulaciones son más graves: "El Primer Ministro noruego, Jens Stoltenberg fue víctima de vandalismo en su biografía de Wikipedia. Descubrió que contenía un buen número de afirmaciones deshonrosas 6 " (Thompson, Bill, 2005) En concreto, el contenido de su artículo, en el que BBC News prefiere no hacer demasiado hincapié, aseguraba que, en su juventud, Stoltenberg había pasado dos años en la cárcel por pedofilia.

$Y$ ya que cualquier usuario puede modificar, editar y corregir un artículo de Wikipedia para gastar una broma e incluso implicar a un político en un grave delito de carácter sexual, ¿Por qué no utilizarla para beneficiar a una empresa? Con esta

6 "Last month Norwegian Prime Minister Jens Stoltenberg found his Wikipedia biography had been vandalised and contained a number of libellous statements" 
idea Microsoft decidió eliminar todo un párrafo del artículo de su consola Xbox 360 en el que se hablaba de errores de funcionamiento. Y Chevron-Texaco (el consorcio petrolífero) borró una entrada sobre biodiésel. (Bitacoras.com en ABC, 2011)

El último hobbie de los internautas es, precisamente, alterar los artículos de Wikipedia de la forma más delirante posible. El objetivo, ofrecer una información surrealista que llame la atención de los medios de comunicación tradicionales y conseguir que te dediquen parte de su espacio y/o tiempo.

Como sucedió tras la entrega de los Premios Oscar 2013. Uno de los personajes habituales en reality shows y espacio de similar pelaje, Sonia Monroy, grababa en Hollywood material para un programa de televisión, $\mathrm{y}$, como parte de dicho proyecto, conseguía colarse durante unos minutos en la alfombra roja más famosa del mundo. Al instante las redes sociales se hacían eco de su "hazaña" y un anónimo internauta (a quién algunos medios que desconocen lo poco que cuesta escribir artículos en wikipedia ascendieron, nada menos que, a la categoría de "hacker") modificaba la "ficha" de Sonia Monroy en la popular enciclopedia online. Según el desconocido la actriz y cantante (que así se define ella misma) había muerto salvajemente tiroteada por el director Quentin Tarantino, quién, al verla sobre la alfombra roja de los Oscar, había actuado de esta manera para "salvaguardar el honor del cine". Durante algunas horas esta pseudo información estuvo al alcance de cualquiera que consultara Wikipedia. (CHIC, 2013)

Es común ver a un periodista consultando en Wikipedia artículos sobre personajes a los que tiene que entrevistar o sobre los que va a escribir. Siempre que veo que alguien lo hace, recuerdo a mis compañeros que los periodistas tenemos otras muchas fuentes de información, aunque no todas nos la ofrezcan de manera tan inmediata.

Cierto es que cada vez hay menos tiempo para elaborar nuestros reportajes y artículos (el usuario ha interiorizado que Internet es inmediato) y para contrastar nuestras informaciones. Sobre todo en el caso de una noticias improgramadas, que son aquellas que se nos presentan de manera imprevista, y que han de distribuirse enseguida. Por ejemplo, los fallecimientos de personajes públicos. Un campo en el que tengo experiencia. En los últimos años he cubierto para el área de actualidad y magazines de Televisión Española la muerte de actores, productores y directores españoles como Luís García Berlanga, José Luís López Vázquez, Antonio Ozores, María Isbert, Manuel Alexandre, Valerio Lazarov... y elaborado reportajes sobre artistas extranjeros como Elizabeth Taylor, Paul Newman o Michael Jackson.

Minutos después de conocerse todos y cada uno de estos fallecimientos los diarios digitales tienen la noticia en portada. Fallecimiento y biografía del personaje. Ambos elaborados por la agencia EFE. La necesidad de inmediatez es tal que ningún medio desea descolgarse de los demás, todos ellos necesitan informar a los internautas, aunque sea con una noticia de agencia, mientras sus redactores elaboran su propia información.

El día que falleció Augusto Algueró agencias y prensa digital destacaban su faceta como compositor de música ligera. "El padre de la chica ye-ye" titulaban en la web de la revista Fotogramas. Y el resto de medios desgranaban la lista de sus canciones: "Tómbola", "Trébole", "Penélope", "Estando contigo" y "Vivo cantando". 
Pero "Vivo cantando" no fue creación de Algueró, sino de Aniano Alcalde. Algueró fue, simplemente, autor de los arreglos para su puesta en escena en el Festival de Eurovisión de 1969.

Atribuir "Vivo cantando" a Augusto Algueró es una equivocación que cometimos casi todos los medios de comunicación que utilizamos Internet como fuente de información aquel día. ¿El origen del error? Imposible averiguarlo, porque en Internet, como afirma Pablo Bozckowski, se produce un proceso de "clonado" de la información. (Vid Bozckowki, Pablo, 2010)

Y este proceso de "clonado" tiene como consecuencia un progresivo empobrecimiento de los contenidos. En primer lugar por ser redundantes, en segundo, porque además de plagiarse las ideas originales y los datos exactos, se plagian los falsos:

"La visibilidad que ofrece la edición continua reduce al mínimo el tiempo de la novedad y conduce a sorprendentes semejanzas, tanto en los enunciados como en el desarrollo de la información, de medios que compiten entre sí. [...] Se rompe así el carácter exclusivo de las primicias, los scoops periodísticos, y aumenta, fruto de la observación de los medios entre sí, el clonado de los aciertos y errores, esto es, la sedimentación noticiosa redundante" (Díaz Nosty, Bernardo, 2011:6)

El fenómeno del "clonado" que mencionan Pablo Bozckowski y Bernardo Díaz Nosty se hace especialmente evidente entre los blogs, sobre todo cuando éstos pretenden imitar a los medios de comunicación. Apenas unos minutos después de que el teletipo de Agencia EFE informase a las redacciones acerca del fallecimiento del actor Juanito Navarro, ya podía leerse la noticia en todos los medios digitales (y al igual que sucedió con la muerte de Augusto Algueró, todos publicaron el despacho de EFE íntegro hasta que elaboraron uno propio). Poco después un malintencionado internauta modificaba el artículo del actor en la página web Wikipedia, adjudicando a Juanito la paternidad de un popular periodista y presentador español: Pepe Navarro.

En esta ocasión el error era bastante más evidente, al menos para los periodistas, ningún medio (digital o no) cayó en la trampa. Quienes sí lo hicieron, en cambio, fueron los bloggers, ellos no sólo se fiaron de la información de Wikipedia, sino que utilizaron su texto redactado, lo copiaron, y lo pegaron en sus blogs 7 . Los autores de Nostalgia bajo la lluvia, Verfamosos y Supermallamerica, entre otros, "clonaron" el texto de su fuente, reproduciendo el error (Imágenes 3, 4 y 5).

${ }^{7}$ La siguiente frase: "En 1960-1961 Juanito Navarro bate récord de permanencia y taquilla en Madrid, Teatro Alcázar desde 10 de abril hasta 20 de septiembre de 1960. Cuatro temporadas de éxito con su Compañía de Comedias Cómicas" aparecía ese día, tal cual, en numerosos blogs consultados. 


\section{Imagen 3}

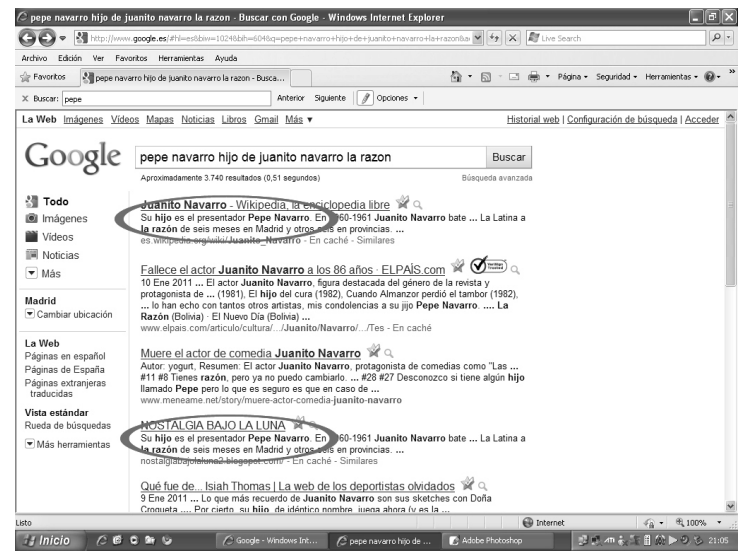

Imagen 4
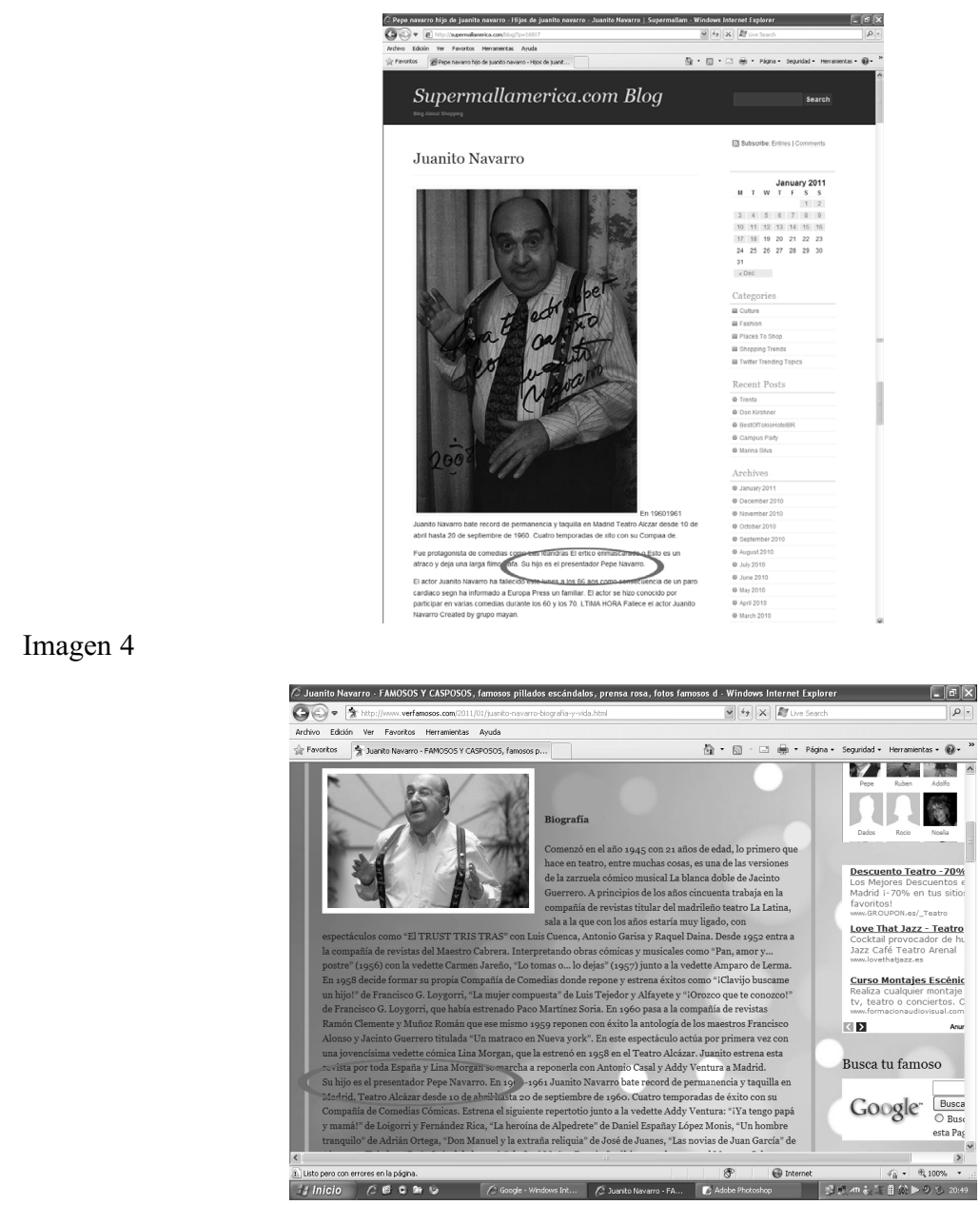

Imagen 5

CIC Cuadernos de Información y Comunicación 


\section{LOS NIÑOS BUENOS HACEN LOS DEBERES...}

Dice un viejo refrán que incluso el mejor escriba hace un borrón y también suele decirse que sólo rompe platos quién anda con la vajilla. Es inevitable equivocarse. Pero quién no contrasta la información que le proporcionan sus fuentes está predestinado a cometer más errores.

CNN creyó a pies juntillas la broma que le gastaron Rick Dyer y Matt Whitton en verano de 2008. Los dos aseguraron haber hallado el cuerpo de Pie Grande, el mítico sasquatch de las montañas, buscado en Estados Unidos y Canadá desde 1971 (CNN, 2008/1). Una semana después de causar el revuelo con su burla Dyer y Whitton confesaron la verdad. Ellos aparecieron como farsantes ante la opinión pública y CNN quedó en ridículo. (CNN, 2008/2)

Una simple llamada telefónica le hubiese bastado a Manuel Saco Cid, colaborador del diario 20 minutos, para descubrir que lo que acababa de leer en una página web no era noticia, sino sátira. El Mundo Today, web de humor con canal de televisión y suplemento dominical incluidos, publica disparatadas noticias: "Cataluña será independiente el primer domingo de cada mes", "Hacienda advierte que las niñas bonitas también pagarán dinero" o "El cártel colombiano traficará con droga sin gluten" son algunos de los delirantes titulares que ofrecen. Manuel Saco leyó uno de ellos "Adolfo Domínguez diseñará el nuevo uniforme del Ku Klux Klan", se escandalizó, ahondó en la noticia, su indignación fue en aumento y finalmente escribió una columna criticando al diseñador gallego por su última y polémica aventura empresarial.

Hoy, en lugar de la desafortunada noticia, se pueden leer las disculpas del periodista. (20 minutos, 2009) "Mi torpeza" escribe "fue la utilización de lo que solemos llamar en periodismo una fuente contaminada". El Mundo Today no es una "fuente contaminada", podríamos aclararle, sino una web satírica cuya razón de ser es hacer reír. Por supuesto que la información era falsa, todas lo son: esa es su vocación.

Evitar errores como éstos es posible. No se trata de volver a hacer fuego con dos cantos rodados. No proponemos una vuelta al ludismo, aquel movimiento que en tiempos de la Revolución Industrial llevaba a los obreros a destruir las máquinas porque les dejaban, literalmente, en paro. Internet nos puede conducir a páginas con información fiable, sellos de garantía y autores bien identificados, con nombres y apellidos. Lo fundamental es, usemos las fuentes que usemos, que no perdamos de vista las normas básicas del buen periodismo.

Lo esencial, para Nemesio Rodríguez, Agencia EFE, es "ese código ético y deontológico que está en la misma esencia de nuestra profesión: la búsqueda de la verdad con rigor, independencia y verificación de los hechos" y que ningún avance tecnológico puede "alterar, porque, como dice Guillermo Altares, ElPais.com: "Las normas del viejo periodismo son igual de válidas (o tal vez más) en el nuevo, porque son las que distinguen a los auténticos medios de comunicación de los falsos". Internet puede modificar el escenario mediático pero, en opinión de Carlos González Reigosa: (miembro del Consejo de Redacción de Cuadernos de Periodistas, la Revista de la Asociación de la Prensa de Madrid) "Esto no quiere decir que se haya merendado legítimamente los contenidos de los mejores libros de estilo del mundo 
[...] Internet es imprescindible, lo que no es imprescindible es que deteriore las exigencias de veracidad o rigor apuntaladas por el buen periodismo" (Cuaderno sde Periodistas, 2010)

Es hora de recuperar el prestigio y la credibilidad del público. Si el periodismo está en crisis, que sea por causas económicas, no porque el pueblo no nos vea preparados, o no se fíe de nosotros.

\section{BIBLIOGRAFÍA Y PÁGINAS WEB CONSULTADAS}

Boczkowski, Pablo (2010) News at work: Imitation in an age of information abundance. Chicago: University of Chicago Press

Dízz Handino, M. Pilar (Dir y Coord) (2007) Periodismo en la era de Internet. Claves para entender la situación actual de la información periodística en España. Barcelona: Ariel para Fundación Telefónica

Cuadernos de Periodistas(2010) "La práctica periodística en los nuevos medios" (entrevistas) en Cuadernos de periodistas. Revista de la Asociación de la Prensa de Madrid, núm 21, diciembre de 2010

Martínez Albertos, José Luis y Santamaría SuÁrez, Luisa (1996) Manual de estilo. Indianápolis: Inter American Press Books.

MenCHER, Melvin (2003) News reporting and writing. McGraw-Hill

RuBio, Noelia (2001) "Los periodistas usan Internet aunque les parece poco fiable" en Ciberpais (El Pais) (Publicado el 28 de junio de 2001)

TuChMAn, Gaye (1998-1999) "La objetividad como ritual estratégico: un análisis de las nociones de objetividad de los periodistas" en CIC, Cuadernos de Información y Comunicación, número 4, 1998-1999, Madrid: Universidad Complutense, pp. 31-60

20 Minutos (2009) "Pido disculpas a Adolfo Domínguez y a los lectores", en 20 minutos: http://blogs.20minutos.es/manolosaco/2010/02/20/pido-disculpas-adolfodomaanguez-y-los-lectores/ (Consultado el 13 de marzo de 2013)

ASNE (1998) "Editors group realeases preliminary journalism credibility study", en Asne: http://asne.org/kiosk/news/98jep.htm (Consultado el 1 de Julio de 2012)

ASNE (1999) "The findings in brief" en Asne:

http://asne.org/kiosk/reports/99reports/1999examiningourcredibility/p56 findings.html

(Consultado el 1 de Julio de 2012)

Bitácoras(2011) "Los gazapos más sonados de la Wikipedia" en $A B C$ : http://www.abc.es/20110114/medios-redes/abci-gazapos-wikipedia201101131919.html (Consultado el 19 de marzo de 2013)

CHIC (2013) “QQué hacía Sonia Monroy en los Oscar 2013?” en LibertadDigital: http://www.libertaddigital.com/chic/corazon/2013-02-26/que-pinta-sonia-monroyen-los-oscar-2013-1276483342/ (Consultado el 19 de marzo de 2013)

CNN (2008/1) "Body proves Bigfoot no myth, hunters say" en CNN: http://edition.cnn.com/2008/US/08/14/bigfoot.body/index.html (Consultado el 19 de marzo de 2013 
CNN (2008/2) "Bigfoot hoaxer say it was just a big joke" en CNN: http://edition.cnn.com/2008/US/08/21/bigfoot.hoax/ (Consultado el 19 de marzo de 2013)

Delclós, Tomás (2011) “Wikipedia, 10 años y 278 ediciones” en Ciberpaís (El País) http://www.elpais.com/articulo/Pantallas/Wikipedia/anos/278/ediciones/elpepirtv/2 0110111elpepirtv 2/Tes (Consultado el 19 de marzo de 2013)

DíAz Nosty, Bernardo (2011) "Los nuevos escenarios de la prensa" (Conf) en Telos. Cuadernos Comunicación e Innovación: http://sociedadinformacion.fundacion.telefonica.com/url-direct/pdfgenerator?tipoContenido $=$ articuloTelos\&idContenido $=2011012509430001 \&$ idioma $=$ es

(Consultado el 19 de marzo de 2013)

EL PAís (2010) "TVE emite imágenes falsas del terremoto de Haití" en El País: http://www.elpais.com/articulo/sociedad/TVE/emite/imagenes/falsas/terremoto/Hai ti/elpepugen/20100114elpepusoc_11/Tes (Consultado el 19 de marzo de 2013)

Ministerio DE EMPleo y Seguridad SOCIAL (2013) "El paro registrado sube en 59.444 personas en febrero", en web del Ministerio de Empleo:

http://prensa.empleo.gob.es/WebPrensa/noticias/laboral/detalle/1884

(consultado el 13 de marzo de 2013)

PRNoticias (2010) "El Mundo despide 164 redactores y los suple con 90 becarios", en Prnoticias: http://www.prnoticias.com/index.php/home/154-el-mundo-unidad-editorial-/10052225-los-sindicatos-denuncian-el-mundo-despide-a-164-personas-ylos-suple-con-90-becarios (Consultado el 20 de marzo de 2013)

RTVE (2010) A la carta: Telediario 2 - 13/01/10, en RTVE.es: http://www.rtve.es/alacarta/videos/telediario/telediario-2-13-01-10/668073/\# (Consultado el 19 de marzo de 2013)

Thompson, Bill (2005) "What is it with Wikipedia?" en BBC News: http://news.bbc.co.uk/2/hi/technology/4534712.stm (Consultado el 19 de marzo de 2013)

ToLEDO, Daniel (2009) "El beneficio de la prensa escrita se desploma y cae un $98 \%$ en el año 2008", en El Confidencial:

http://www.elconfidencial.com/comunicacion/beneficio-prensa-desploma20091215.html (Consultado el 20 de marzo de 2013) 


\title{
RESUMEN
}

"No sé cómo trabajábamos antes sin Internet" Es una frase que los periodistas escuchamos (y pronunciamos) constantemente. Nos resulta tan habitual utilizar la Red como fuente de información que apenas recordamos cómo trabajábamos cuando no estaba a nuestro alcance. Esta herramienta tan valiosa que tanto facilita nuestro día a día es un arma de doble filo. Los periodistas parecemos haber olvidado algunas de nuestras normas clásicas, por ejemplo la que nos obliga a contrastar toda información. Desde que Internet ha aparecido en nuestras vidas nos equivocamos más.

Palabras clave: Internet, Fuente de información, Deontología, Error, Bulo

\begin{abstract}
"I don't know how we worked before Internet" Is something that journalist use to listen (and to declare) often. Using the World Wide Web is so habitual that we don't remember how we were working when it isn't exists. This valuable tool, which greatly facilitates our daily work is a two-edged weapon. Journalists seem to have forgotten some of our classic standards, for example, that we must compare all information. Since the Internet has appeared in our lives we make more mistakes
\end{abstract}

Keywords: Internet, Information research, Business ethics, Mistake, Hoax

\section{RÉSUMÉ}

"Je ne sais pas comment l'on travaillait avant l'Internet" est une phrase commune entre les journalistes. Au jourd'hui l'utilisation de l'Internet est si habituelle que les professionnaux ne se souviennent pas même comment est-ce qui' ils travaillaient quand elle n'existait pas. Cet endroit valieux, que fait infinimment plus simple le travail des journalistes, est en train de devenir une arme à deux fils. Les journalistes commencent a perdre de vue ses règles classiques, par example, la comparation des informations. Dès l'arrivée de l'Internet les journalistes font de plus en plus plus d'erreurs.

Most clé: Internet, source de l'information, l'étique, erreur, rumeur 